Volume 8. No. 1.1, 2020

International Journal of Emerging Trends in Engineering Research

Available Online at http://www.warse.org/IJETER/static/pdf/file/ijeter1581.12020.pdf

https://doi.org/10.30534/ijeter/2020/1581.12020

\title{
Determining Islanding Operation Using Micro Grid Phasor Measurement Unit Parameters
}

\author{
Ahmed Amirul Arefin ${ }^{1}$,Khairul Nisak Md Hasan ${ }^{2}$, Mohd Fakhizan Romlie $^{3}$, Mohd Faris Abdullah $^{4}$, Mohd Nazri Ali ${ }^{5}$, and \\ Mohammad Lutfi Othman ${ }^{6}$ \\ ${ }^{1,2,3,4}$ Department of Electrical and Electronics Engineering, Universiti Teknologi PETRONAS, Perak, Malaysia, \\ ${ }^{2}$ khairulnisak.hasan@utp.edu.my \\ ${ }^{5}$ PRefChem, Pengerang, Johor, Malaysia \\ ${ }^{6}$ Advance Lightning Power and Energy Research (ALPER), Department of Electrical and Electronics Engineering, Universiti
}

Putra Malaysia, Selangor, Malaysia

\begin{abstract}
For improving the reliability of the micro grid network, a robust islanding detection algorithm is required. For creating a vigorous islanding detection algorithm voltage angle and current angle should be detected appropriately from the grid. The main objective of this research is to determine and compare the voltage angle and current angle with normal operation and islanding operation of the micro grid to develop multilevel islanding detection algorithm to ensure the higher reliability. In this work, IEEE 30 bus network phasor measurement unit parameters have been determined in PowerWorldSimulator. The result shows that the proposed methodology can appropriately determine the islanding event and the comparative study shows an incredible change in phasor measurement unit parameters when grid goes on islanding operation.
\end{abstract}

Key Words :Phasor Measurement Unit (PMU), voltage angle, current angle, micro grid.

\section{INTRODUCTION}

Islanding is the condition when a portion of the power system, which includes both generations and loads persistently working while this portion electrically isolated from the main system [1]. The main downside of the islanding is safety threat for utility workers who may not concern that circuit is still powered. Islanding event may occur in the both transmission and distribution levels. In islanding event one portion of the loads and generators become isolated from the actual grid. In the islanding event bus voltage/current angle strongly influence to make the system unstable and unreliable. For instance, fast and appropriate islanding detection method is required for the electrical power grid.

Phasor Measurement Unit (PMU) based islanding detection is one of the new parts in the grid protection for the bulk power system and it is different from the conventional scheme. A PMU can generate 2.6 billion data by 30 samples/second [2]. The generated data are magnitude and angle of the voltage and current inclusion system frequency. Since PMU generates this large amount of non-stationary data it needs a robust algorithm for extracting the data to detect abnormal events in the grid. In [3]they have presented a comprehensive survey on PMU's application in distribution system and they found for islanding detection PMU's could be one of the significant applications. For the islanding detection SCADA system is unable to respond accurately due to communication delay and also SCADA system require higher investment for implementation. In $[4,5]$ they have developed an islanding detection algorithm using voltage angle and current which lessened false triggered during the islanding event but due to the higher number of required communications makes the completing steps higher. In [6] they have originated an islanding detection algorithm based on voltage and current angle but due to the inappropriate threshold setting false triggered remained. A cost-effective voltage angle-based islanding detection has been proposed in [7] where they improvised the completing time but absent of comparative study between islanding and normal operation.

An islanding detection algorithm for Distributed Generator (DG) has been developed using voltage angle in [8] the scheme commitment of this plan is that simple to execution but inappropriate threshold has made the scheme less reliable. In $[9,10]$ they have proposed an islanding detection scheme based on phasor and frequency which reduced the false triggered but longer detection time due to inaccurate data accommodation. A probabilistic principle component analysis-based islanding detection has been developed in $[11,12]$ using phasor and frequency input from PMU and the detection time is faster but when the value of phase angle and frequency are well matched during the islanding event the scheme collapsed. In [13] they have proposed a modified differential evolution algorithm for preventing DG from islanding event and differentiate other events. An islanding recognition procedure has been proposed for three stage lattice associated photovoltaic inverter framework dependent on multi signal investigation technique [14]. The principle commitment of this proposed technique is computational time has been diminished. In this context, the objective of this study is to develop a waveform focused islanding detection scheme using phasor measurement unit. 


\section{METHODOLOGY}

Phasor Measurement Unit (PMU) can estimate angle and magnitude of voltage and current along with the frequency as well. For instance, voltage angle and current angle have been considered since they are very sensitive parameters when power grid unintentionally goes to the islanding operation. In this study, PowerWorldSimulator software has been used for designing and simulating purpose and transmission line limits as equivalent amps derived from MVA ratting using below equation:

$$
\text { AmpRatting }=\frac{\text { MVARatting }}{\sqrt{3} \times \text { BaseKV}} \times 1000(1)
$$

Transmission line parameters has been utilized to determining the current angle in both islanding and normal operation. A brief methodology has been described in Figure 1. which has started from the designing unit where micro grid system has been designed with defining the slack bus.

In the second stage. different level distribution has been created where first need to define the transformer from the designed network. Then a transformers combination needs to design where at a time only two transformers from the network can goes to the operation during that time rest of the transformer will be remained closed. Third stage is for creating islanding operation by isolating the generator or load bus from the main grid. There are four power flow methods and those are; Full Newton, Fast Decoupled, Polar NR Power Flow, Gauss-Seidel. For running the simulation needs to perform any single method.

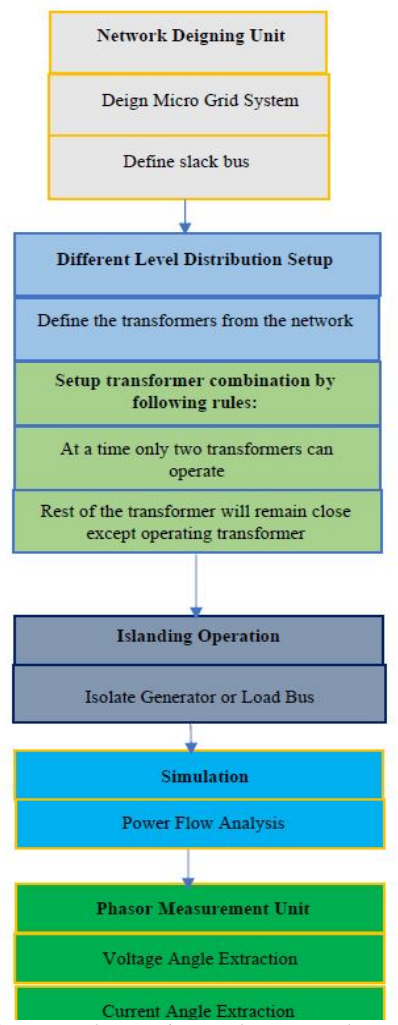

Figure 1: Methodology to determine voltage angle and current angle of the islanding event
Voltage angle and current angle will be determined from the phasor measurement unit after performing the power flow analysis. Once voltage angle and current angle determined from phasor measurement unit it can be used for originating robust islanding detection algorithm for improving the micro grid reliability.

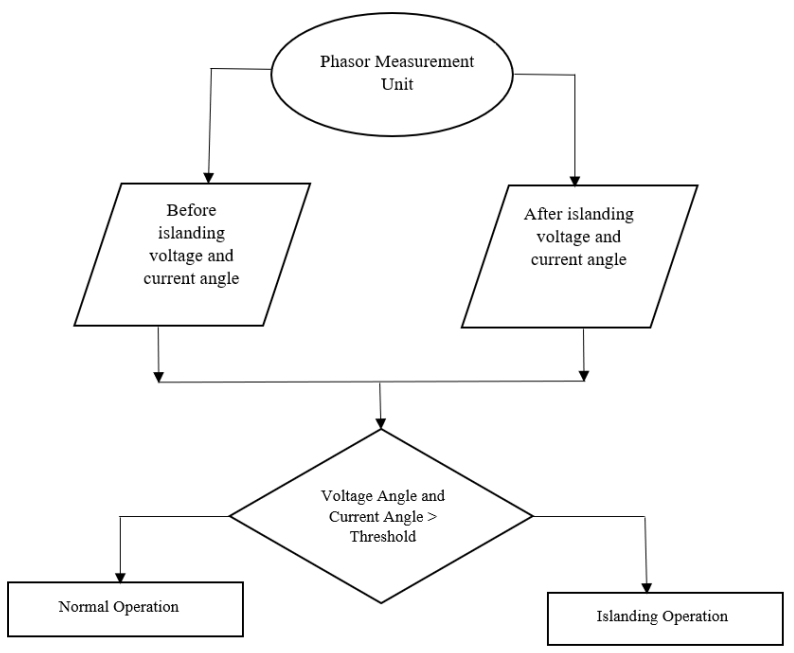

Figure 2:Flow chart to determine islanding operation from phasor measurement unit data

Figure 2, presents that after getting voltage angle and current angle data from phasor measurement unit. A threshold needs to set after several attempts and if the calculated data is greater than threshold then it will be considered as islanding operation otherwise it will detect as normal as normal operation.

In this work, IEEE 30 Bus system has been designed in PowerWorld Simulator software. IEEE 30 bus consists 6 synchronous machine, IEEE Type-1 exciters, 36 buses and 37 transmission line, 10 transformers, consistent impedance load is 37, 283.4 MW and 126.2 MVAR of total load demand and 4 synchronous compensators.

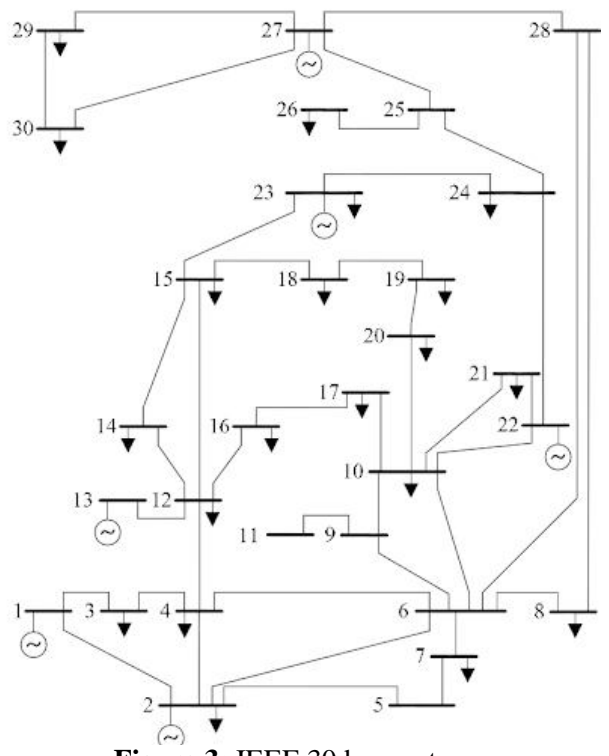

Figure 3: IEEE 30 bus system 
Full Newton power flow method has been performed for simulating the before and after islanding event. Performed power flow study in normal operation data has been compared with [15]. For creating the islanding event, A $40 \mathrm{MW}$ generator and $22 \mathrm{MW}$ load in bus 2 has been isolated from the main grid. The clock has been setup under the bus parameters. For evaluating the microgrid resilience and different distribution a transformer combination has been setup and performed.

\section{RESULTS AND DISCUSSIONS}

Table 1. presents $132 \mathrm{KV}$ nominal buses voltage and current angle along with waveform plots between islanding and normal operation. In the plot red waveforms are indicating before islanding event and blue waveforms are indicating after islanding event.

Waveforms are describing the significant changes when grid goes to the islanding operation for a certain period and this islanding have been detected from the waveforms after performing power flow study. In bus number 1 voltage angle remained unchanged in both situation but current angle showed a significant change when it goes to the islanding operation. If we give proper shadow on other generator buses then we will see no buses have remained unchanged voltage angle value in both situation except bus number 1. Basically, this bus 1 is connected with the slack bus by a transformer. An immense change happened when system goes to the islanding operation. Plots are clearly showing the difference of before islanding and after islanding event.

Table 1: IEEE 30 Bus voltage and current angle applying full Newton power flow analysis

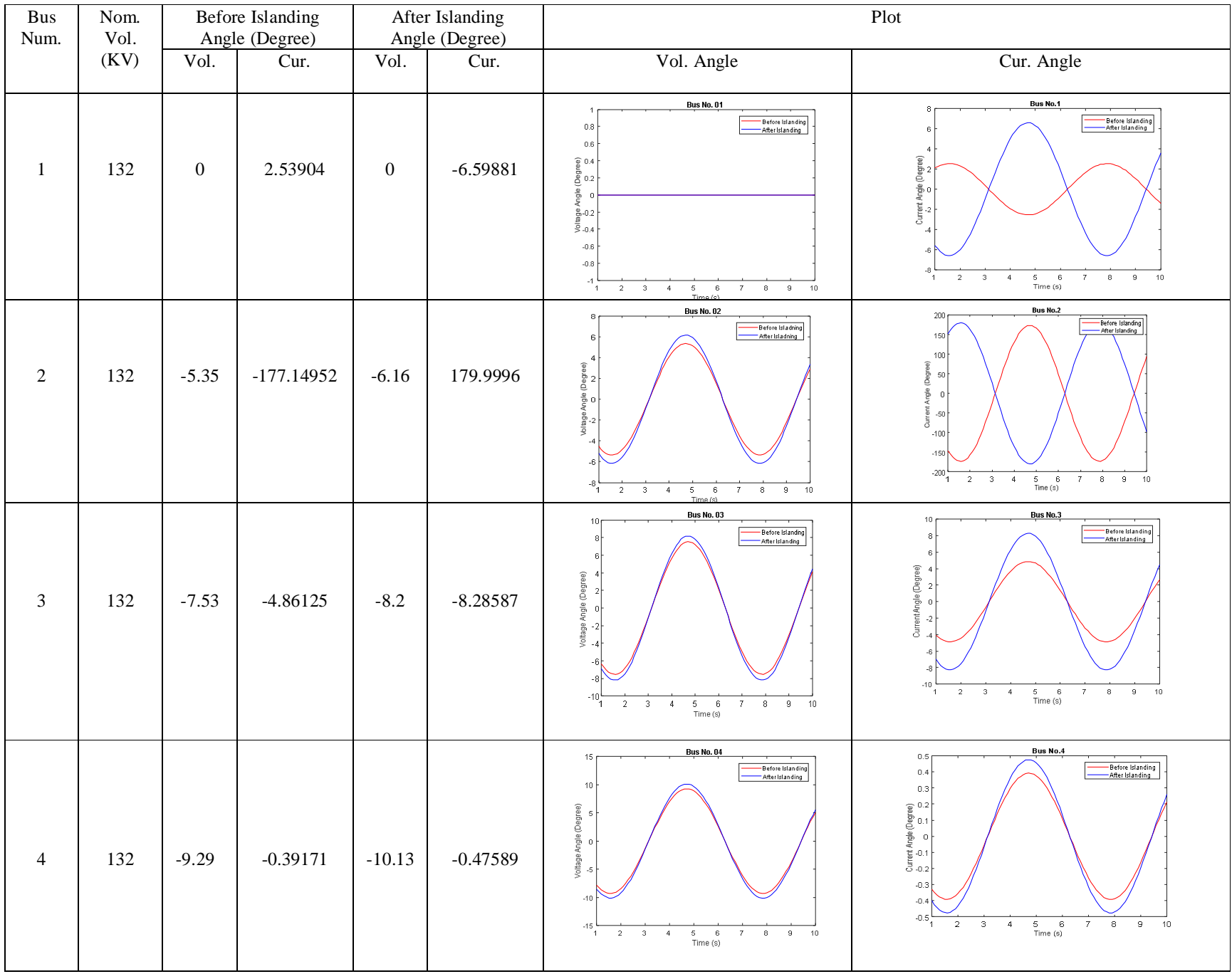


Ahmed Amirul Arefin et al., International Journal of Emerging Trends in Engineering Research, 8(1.1), 2020,97 - 101

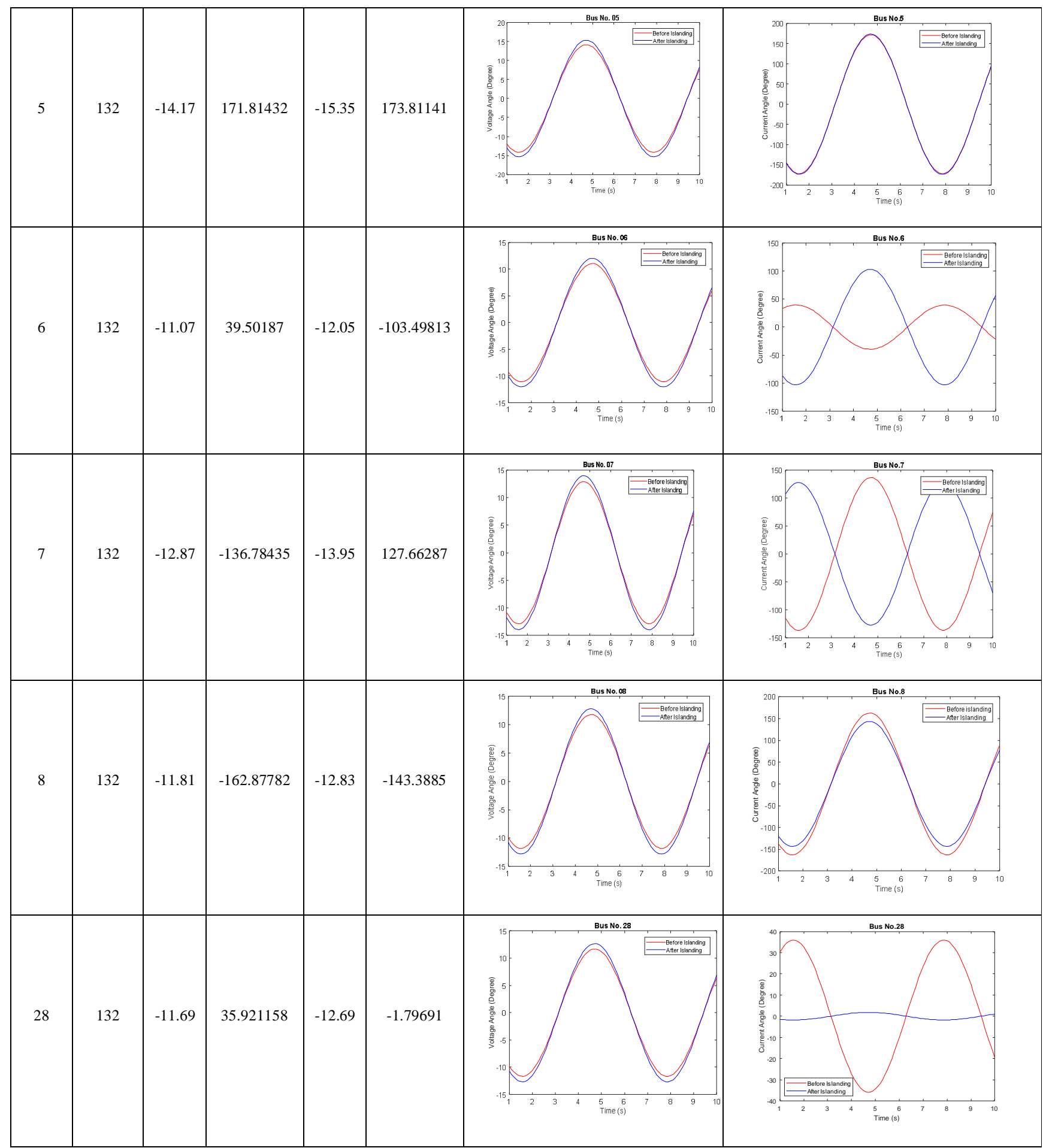

IEEE 30 bus system is a bulky power system which definitely require to maintain a stable and unchanged situation but when an islanding event operate it is always challenging task but setting the threshold precisely then we can prevent system from the islanding event. This noncomplex islanding determining scheme can be highly applicable for the private microgrids (i.e.; factory, hospital, office buildings). 


\section{CONCLUSION}

In this study, a methodology has been discussed to develop a waveform focused islanding detection scheme using phasor measurement unit. Comparative analysis of those operation presents that when the grid unintentionally goes to the islanding operation an enormous fluctuation occurs in the grid. In this work, islanding operation have been identified from the waveforms which is created from performing the power flow analysis. This study surely will enhance the scope and efficacy of the phasor measurement unit-based islanding detection scheme.

\section{ACKNOWLEDGEMENT}

The work was funded and supported by YayasanUniversiti Teknologi PETRONAS (YUTP) grant No. YUTP-015LC0167.

\section{REFERENCES}

[1] P. Mukhopadhyay, S. Patil, A. Rajkumar, S. Chitturi, C. Kumar, A. Jain, and S. Gupta.Islanding detection of interconnected grids based on synchrophasor measurements (PMU), In 2014 6th IEEE Power India International Conference (PIICON), pp. 1-6, December 2014.

[2] S. M. A. Bhuiyan, J. F. Khan, and G. V. Murphy. Big data analysis of the electric power PMU data from smart grid,Conf. Proc. - IEEE SOUTHEASTCON, pp. 1-5, March 2017.

[3] M. Hojabri, U. Dersch, A. Papaemmanouil, and P. Bosshart.A Comprehensive Survey on Phasor Measurement Unit Applications in Distribution Systems,Energies, vol. 12, 2019.

[4] D. Kumar, and P.S. Bhowmik. Wide area islanding detection using phasor measurement unit, In IEEE 11th International Conference on Intelligent Systems and Control (ISCO), pp. 49-54, January 2017.

[5] H. Chen, K. Martin, B. Bhargava, V. Budhraja, and J. Balance. On-line islanding detection application in the RealTime dynamics monitoring system, In IEEE PES T\&D Conference and Exposition, pp. 1-4, April 2014.

[6] J. Y. Zhang and C. M. Bush.PMU based islanding detection to improve system operation, IEEE Power Energy Soc. Gen. Meet.,pp. 1-5, July 2016.

[7] S. Dutta, P. K. Sadhu, M. J. B. Reddy, and D. K. Mohanta.Smart inadvertent islanding detection employing p-type $\mu \mathrm{PMU}$ for an active distribution network",IET Generation, Transmission \& Distribution, vol. 12, pp. 4615-4625, 2018.

[8] S. Skok, K. Frlan, and K. Ugarkovic. Detection and Protection of Distributed Generation from Island Operation by Using PMUs. Energy Procedia, vol. 141, pp. 438-442, 2017.

[9] Z. Lin, T. Xia, Y. Ye, Y. Zhang, L. Chen, Liu, and F. Wen.Application of wide area measurement systems to islanding detection of bulk power systems, IEEE Transactions on Power Systems, vol. 28, no.2, pp. 2006-2015, 2013.

[10] K. Narayanan, S. A. Siddiqui, and M. Fozdar. Hybrid islanding detection method and priority-based load shedding for distribution networks in the presence of DG units,IET Generation, Transmission \& Distribution, vol. 11, no. 3, pp.586-595, 2017.

[11] X. A. Liu, D. Laverty, and R. Best. Islanding detection based on probabilistic PCA with missing values in PMU data, In IEEE PES General Meeting Conference \& Exposition, pp.1-6, July 2014.

[12] X. Liu, J.M. Kennedy, D. M. Laverty, D. J. Morrow, and S. McLoone. Wide-area phase-angle measurements for islanding detection-An adaptive nonlinear approach, IEEE Transactions on Power, vol.31, no.4, pp.1901-1911, 2016.

[13] M. Ahmadipour, H. Hizam, M. L Othman, and M. A. Radzi.Islanding detection method using ridgelet probabilistic neural network in distributed generation. Neurocomputing, vol. 329, pp.188-209, 2019.

[14] M. Ahmadipour, H. Hizam, M. L. Othman, M. A. M Radzi., and A. S. Murthy,Islanding detection technique using Slantlet Transform and Ridgelet Probabilistic Neural Network in grid-connected photovoltaic system, Applied Energy, vol.231, pp.645-659, 2018.

[15] I. Totonchi, H. Al Akash, A. Al Akash, and A. Faza. Sensitivity analysis for the IEEE 30 bus system using load-flow studies. In IEEE 3rd international conference on electric Power and energy conversion systems, pp.1-6, October 2013. 